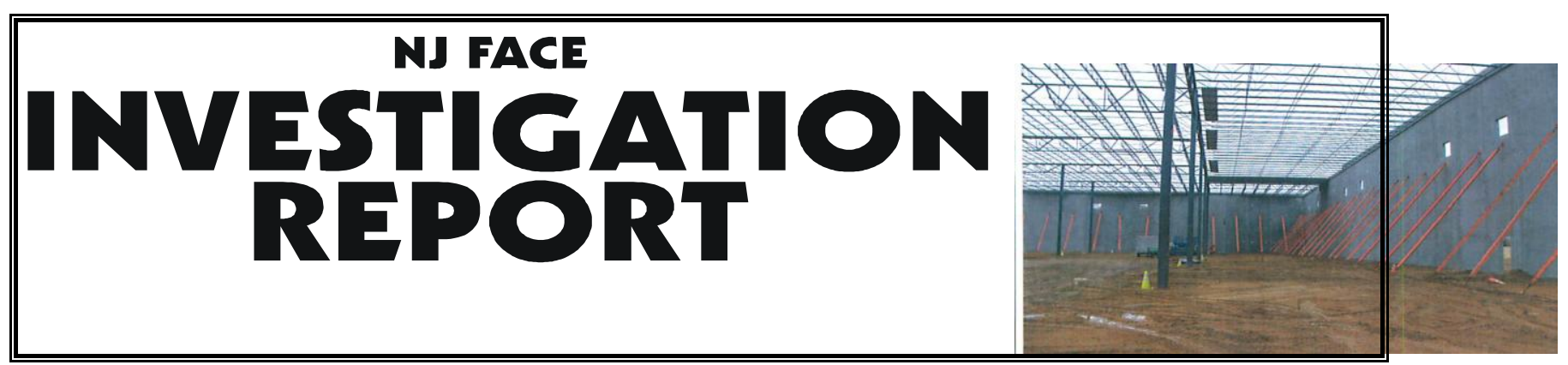

Fatality Assessment \& Control Evaluation Project

FACE 09-NJ-099

October 15, 2012

\title{
Hispanic Construction Worker Wearing Fall Protection Dies after Falling 40 Feet from Roof
}

A 51-year-old male Hispanic construction worker died after a 40-foot fall from the roof at an industrial warehouse construction site. On the day of the incident, the decedent was installing corrugated metal roof decking. He was wearing fall protection equipment, which included a harness and a retractable lanyard connected to a metal anchor device. The anchor was attached to the unsecured leading edge of the corrugated decking. When the victim fell off the roof, the force caused the anchor to break free and the victim fell approximately 40 feet to the ground.

Contributing Factors:

- Improper anchor plate was used for the type of decking installed

- Improper screws used to fasten anchor plate

- Anchor plate was mounted on an unsecured edge

NJ FACE investigators recommend that these safety guidelines be followed to prevent similar incidents:

- Utilize the appropriate type of anchor plate when installing corrugated roof decking.

- Anchor plate screws should conform to manufacturer's specifications, including type and length of threading.

- While installing roof decking, the anchor of the fall protection system should not be affixed to an unsecured leading edge.

- A safety and health plan based on a job hazard analysis should be developed by the employer and followed where workers are assigned tasks.

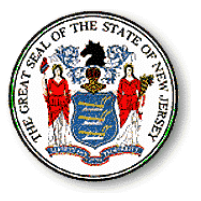

Public Health Services Branch Division of Epidemiology, Environmental and Occupational Health Occupational Health Surveillance Unit (609) 826-4984 nj.gov/health/surv/face/index.shtml 


\section{INTRODUCTION}

In the winter of 2009, NJ FACE staff was notified of the death of a 51-year-old Hispanic male who died after falling 40 feet from a roof at an industrial construction site. The victim was an immigrant from Mexico and had worked as a roofer for several years for a small U.S. construction company. Employee health and safety training, as well as job training, was conducted on site by the employer. A NJ FACE investigator contacted the OSHA Area Office and began the investigation. Additional information was obtained from the medical examiner's report, death certificate, and the OSHA COSHO's report.

\section{INVESTIGATION}

The incident occurred on a clear, cold February day (approximately $32^{\circ} \mathrm{F}$ at the time of the incident). A light covering of snow remained on the ground from a snowstorm that occurred a few weeks prior; the average wind speed for the day was $5 \mathrm{mph}(\mathrm{NW})$, with a maximum of $13 \mathrm{mph}$. The incident occurred at the construction site of a large distribution warehouse. The concrete walls and metal roof truss had been completed (see Figure 1). On the morning of the incident, the metal corrugated roof decking was being installed over the metal roof truss. Two workers were on the roof and were working in tandem to lay the roof decking.

Worker \# 1 (the deceased) was at the leading edge position and wore a retractable lanyard clipped into a 12 " x 10" metal roof anchor device or anchor plate. The plate has 5 " x 9.5" metal attachments that are affixed to an 8 " stem in the plate (see Figure 2). At the end of the attachments is a crossbar, to which the retractable lanyard is clipped. It was noted that this clip and the clip point was undamaged and remained connected throughout the incident (i.e., the retractable lanyard device remained connected to the anchor). In addition, the folded fabric portion of retractable lanyard had its plastic covering and stitching still in-tact. The anchor plate was attached directly to the leading corrugated decking sheet, approximately 18 " from the edge. A standard drill was used to attach the anchor plate with $3 / 4$ " (thread length) screws. According to the manufacturer's instructions, installation of the plate requires 1" [hex washer self-drilling] screws. As determined by OSHA, the employer and employees were under the impression that the screws they used were appropriate because they were 1" in overall length. Worker

\#2 also wore a retractable lanyard, but his fall arrest system was attached to a beam clamp (Figure 3) and was not exposed to the leading edge hazard. 
The employer's protocol for laying corrugated roofing materials requires that the leading edge of the decking not be secured until the next sheet was in place. Each metal sheet was fastened on the following end and anywhere else it was supported by a truss. The next sheet was then placed over the leading edge and attached with fasteners. This was continued until the roof was complete. On the day of the incident, for an unknown reason, the worker fell from the leading edge. When the worker fell and his retractable lanyard reached the end, the anchor plate was pulled completely out of the decking, allowing the worker to fall 40 feet to the ground.

FIGURE 1. Incident site; inside and outside views of construction site.
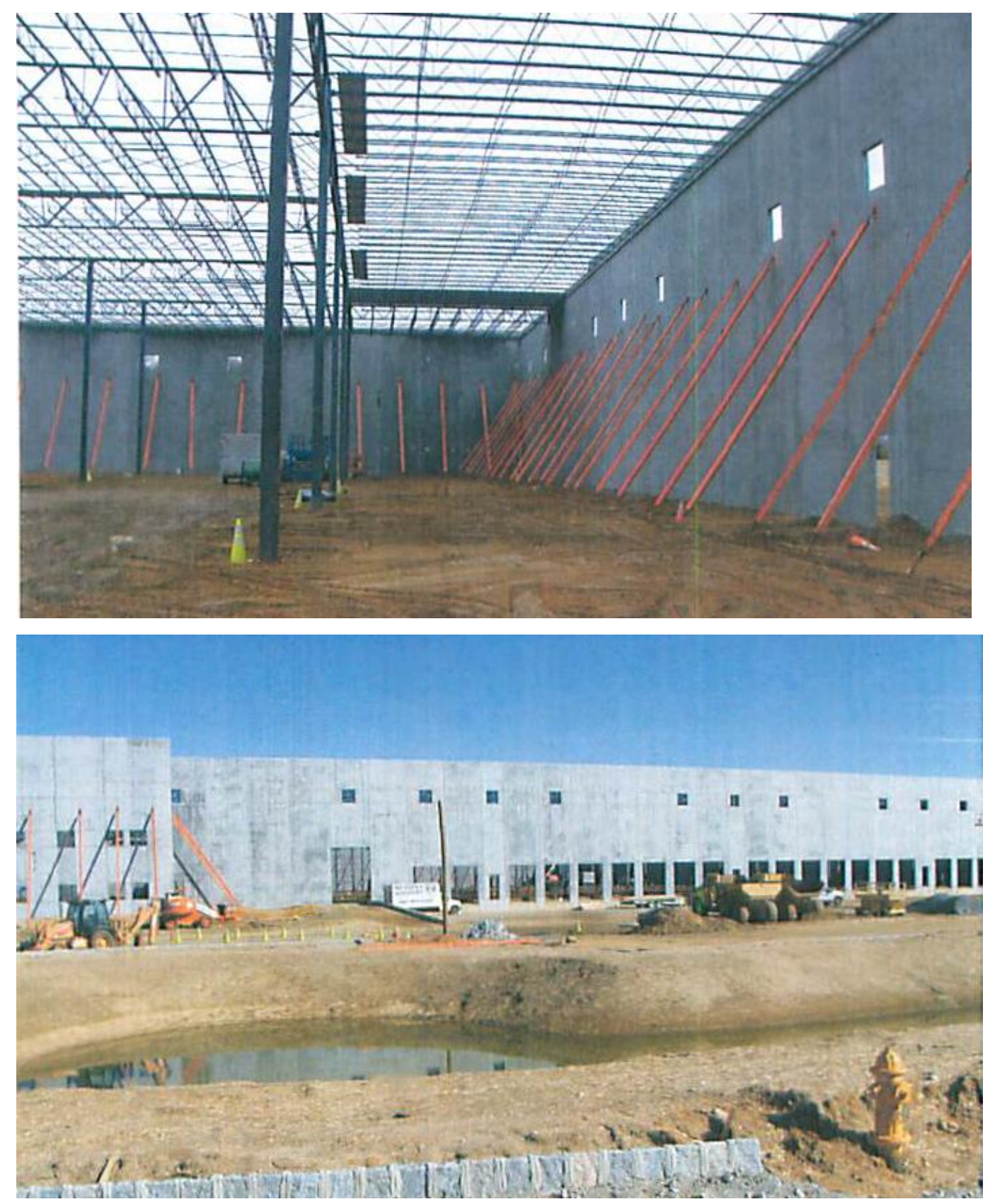


\section{FIGURE 2: Anchor device used by the victim.}

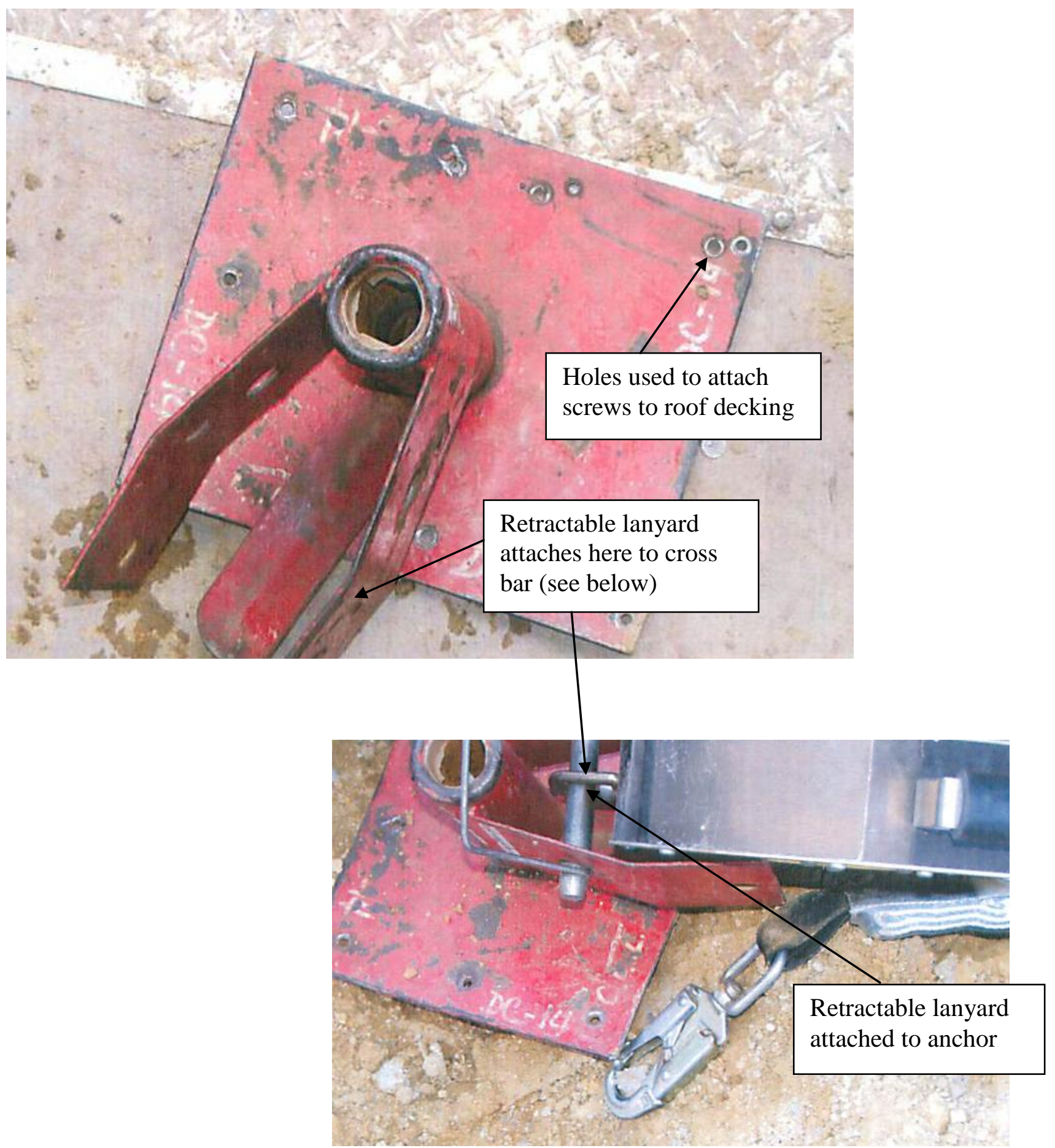


FIGURE 3. View from underneath the roof decking where the victim fell.

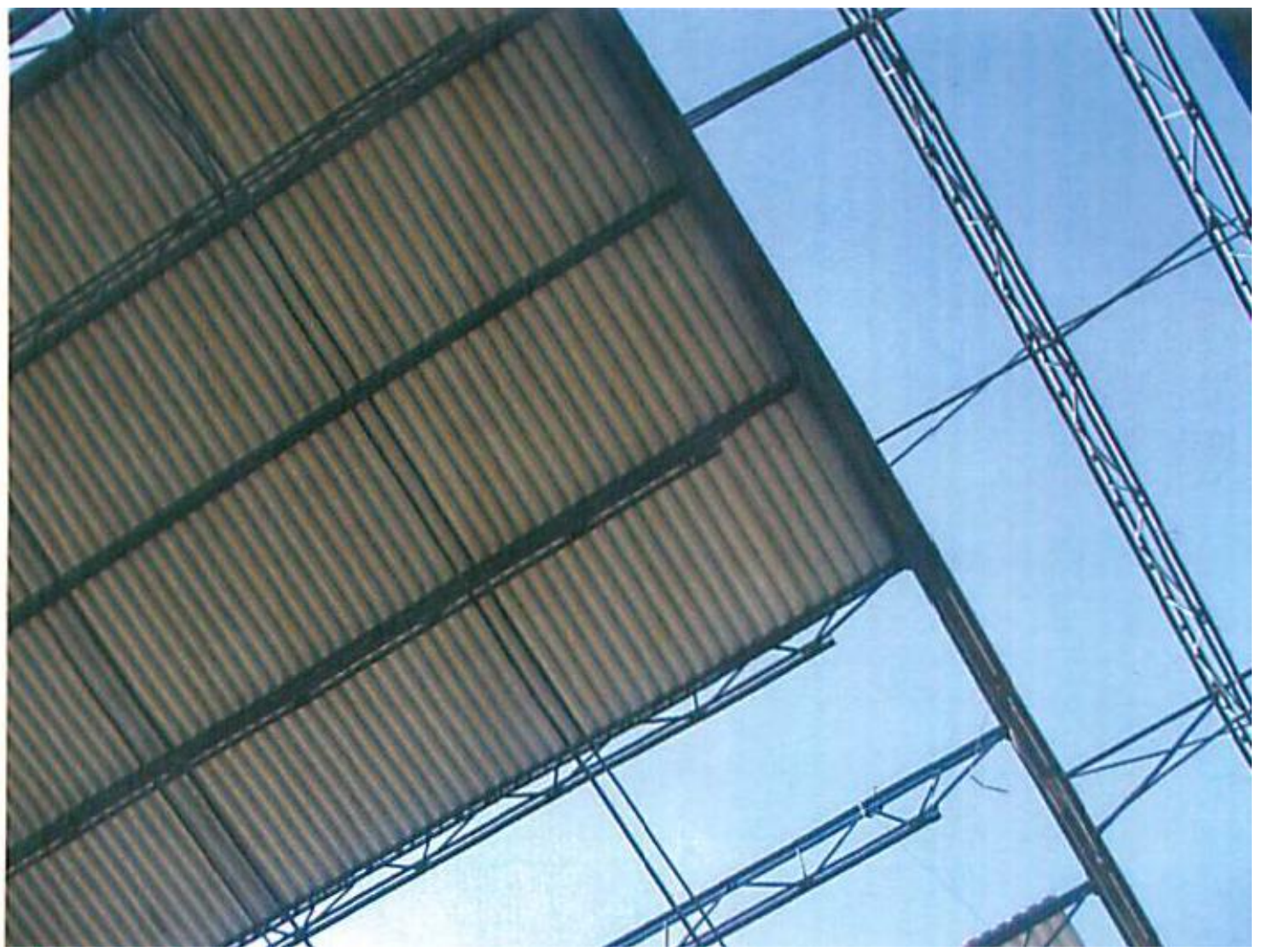

FIGURE 3. Beam clamp to which Worker \#2 was secured.

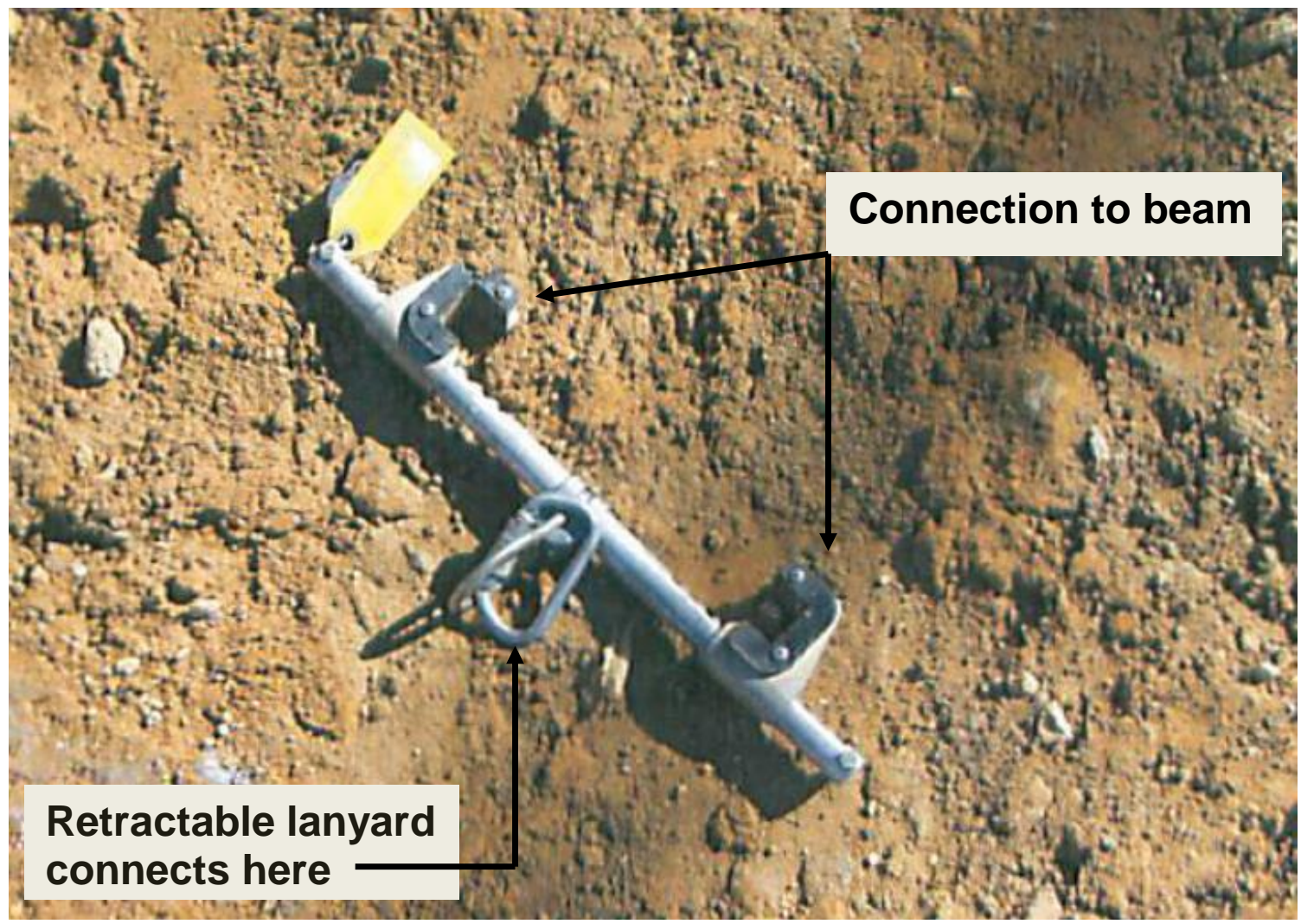


FIGURE 4. Close up view of roof decking to show where anchor plate was installed.

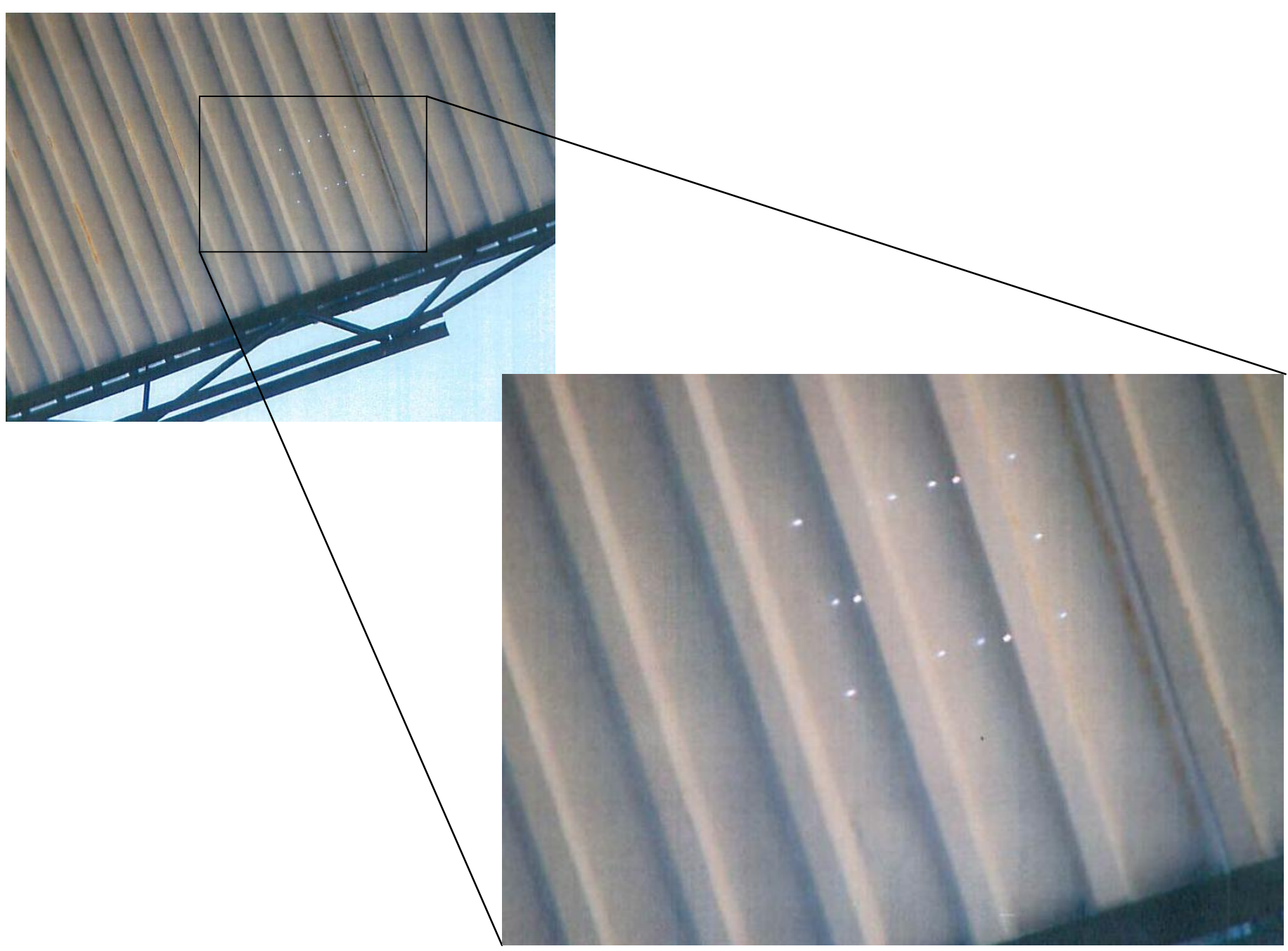




\section{RECOMMENDATIONS/DISCUSSIONS}

Recommendation \#1: Utilize the appropriate type of anchor plate when installing corrugated roof decking.

\section{Discussion:}

According to the manufacturer, the type of anchor used in the incident was intended for use on flat metal roofs and would not adequately arrest a fall if attached to a corrugated roof. The employer was using the manufacturers' directions for a slightly different anchor plate, one that was smaller and meant for flat surfaces.

Recommendation \#2: Anchor plate screws should conform to manufacturer's specifications, including type and length of threading.

\section{Discussion:}

The employee who installed the anchor plate confirmed that screws that were found at the scene were those that he had used during installation. The threaded portions of the screws were $3 / 4$ " in length (with an overall length of 1"). However, the instructions specify that the screw thread should be 1" in length. According to an OSHA interview with the worker who installed the plate, he was under the impression that what they were using was correct since it was 1" in overall length. The extra threading allows for additional turns into the roof deck and truss and would have provided additional strength to the plate.

Recommendation \#3: While installing roof decking, the anchor of the fall protection system should not be affixed to an unsecured leading edge.

\section{Discussion:}

In this case, the anchor plate was located on the unsecured, leading edge of the roof installation. Therefore, when the worker fell from the edge that was not secured to the truss, an upward force was exerted on the anchor plate, forcing the screws out of the plate. NJ FACE recommends that all employees working near an unsecured piece of roofing near a roof edge should be anchored via beam clamp (see Figure 3). This type of personal fall-arrest system would conform with CFR 1926 502(d), which states that a fall protection device should be able to support up to 5,000 lbs.

Recommendation \#4: A safety and health plan based on a job hazard analysis should be developed by the employer and followed where workers are assigned tasks.

Discussion: Employers should conduct a job hazard analysis, with the participation of employees, of all work areas and job tasks. A job hazard analysis should begin by reviewing the work activities for which 
the employee is responsible and the equipment required. Each task is examined for mechanical, electrical, chemical or any other hazard the worker may encounter. Specific to this case, it is recommended that a competent person be assigned to inspect all worksites before tasks begin, to identify fall hazards and to determine the appropriate fall prevention systems for workers.

A source of information on conducting a job hazard analysis is included in the Appendix. 


\section{APPENDIX}

\section{RECOMMENDED RESOURCES}

It is essential that employers obtain accurate information on health, safety, and applicable OSHA standards. NJ FACE recommends the following sources of information which can help both employers and employees:

\section{National Campaign to Reduce Falls in Construction}

This national campaign to prevent falls in the construction industry encourages workers in the construction industry to use the right equipment and work safely to reduce falls. The Campaign is a multi-stakeholder effort under the NIOSH National Occupational Research Agenda (NORA) program.

Web site: http://www.cdc.gov/niosh/construction/stopfalls.html

\section{U.S. Department of Labor, Occupational Safety \& Health Administration (OSHA)}

Federal OSHA can provide information on safety and health standards on request. OSHA has several offices in New Jersey that cover the following counties:

Hunterdon, Middlesex, Somerset, Union, and Warren counties. .732-750-3270

Essex, Hudson, Morris, and Sussex counties $.973-263-1003$

呢 Bergen and Passaic counties 201-288-1700

㩆 Atlantic, Burlington, Cape May, Camden, Cumberland, Gloucester,

Mercer, Monmouth, Ocean, and Salem counties $856-757-5181$

Web site: www.osha.gov

\section{New Jersey Public Employees Occupational Safety and Health (PEOSH) Program}

The PEOSH Act covers all NJ state, county, and municipal employees. Two state departments administer the Act; the NJ Department of Labor and Workforce Development (NJDLWD), which investigates safety hazards, and the NJ Department of Health and Senior Services (NJDHSS) which investigates health hazards. PEOSH has information that may also benefit private employers. NJDLWD, Office of Public Employees Safety

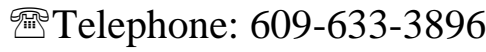

品 Web site: www.nj.gov/labor/lsse/lspeosh.html

NJDHSS, Public Employees Occupational Safety \& Health Program 
留Telephone: 609-984-1863

品 Web site: www.nj.gov/health/peosh

On-site Consultation for Public Employers

留Telephone: 609-984-1863 (health) or 609-633-2587 (safety)

Web site: www.state.nj.us/health/eoh/peoshweb/peoshcon.htm

\section{New Jersey Department of Labor and Workforce Development, Occupational Safety and Health On-Site Consultation Program}

This program provides free advice to private businesses on improving safety and health in the workplace and complying with OSHA standards.

谓Telephone: 609-984-0785

吕 Web site: www.nj.gov/labor/lsse/lsonsite.html

\section{New Jersey State Safety Council}

The New Jersey State Safety Council provides a variety of courses on work-related safety. There is a charge for the seminars.

㑭 Telephone: 908-272-7712.

Web site: www.njsafety.org

\section{Internet Resources}

Other useful Internet sites for occupational safety and health information:

- $\mathrm{CDC} / \mathrm{NIOSH}-w w w . c d c . g o v / n i o s h$

- USDOL Employment Laws Assistance for Workers and Small Businesses - www.dol.gov/elaws

- National Safety Council - www.nsc.org

- NJDHSS FACE reports - www.nj.gov/health/surv/face/index.shtml

- CDC/NIOSH FACE - www.cdc.gov/niosh/face/faceweb.html

- OSHA - www.osha.gov

- ANSI - www.ansi.org

\section{REFERENCES}

- Job Hazard Analysis. US Department of Labor Publication \# OSHA-3071, 1998 (revised). USDOL, OSHA Publications, PO Box 37535, Washington DC 20013-7535 


\section{Fatality Assessment and Control Evaluation (FACE) Project \\ Investigation \# 09-NJ-99}

Staff members of the New Jersey Department of Health, Occupational Health Surveillance Unit, conduct FACE investigations when there is a report of a targeted work-related fatal injury. The goal of FACE is to prevent fatal work-related injuries by studying the work environment, the worker, the task, the tools the worker was using, the energy exchange resulting in the fatal injury, and the role of management in controlling how these factors interact. FACE gathers information from multiple sources that may include interviews of employers, workers, and other investigators; examination of the fatality site and related equipment; and reviewing OSHA, police, and medical examiner reports, employer safety procedures, and training plans. The FACE program does not determine fault or place blame on employers or individual workers. Findings are summarized in narrative investigation reports that include recommendations for preventing similar events. All names and other identifiers are removed from FACE reports and other data to protect the confidentiality of those who participate in the program.

NIOSH-funded state-based FACE Programs include: California, Iowa, Kentucky, Massachusetts, Michigan, New Jersey, New York, Oregon, and Washington. Please visit the NJ FACE Web site at www.nj.gov/health/surv/face/index.shtml or the CDC/NIOSH FACE Web site at www.cdc.gov/niosh/face/faceweb.html for more information.

The NJ FACE Project is supported by Cooperative Agreement \#1 U60 OH0345-01 from the Centers for Disease Control and Prevention (CDC). The contents of this report are solely the responsibility of the authors and do not necessarily represent the official views of the CDC.

Daniel Lefkowitz, PhD

FACE Project Coordinator

Environmental and Occupational Health

Surveillance Program
Jerald Fagliano, $\mathrm{PhD}$

Program Manager

Environmental and Occupational Health

Surveillance Program

Margaret Lumia, $\mathrm{PhD}$

Principal Investigator

Environmental and Occupational Health

Surveillance Program

Public Health Services Branch

Division of Epidemiology, Environmental and Occupational Health

Occupational Health Surveillance Unit

(609) 826-4984

nj.gov/health/surv/face/index.shtml 